LA-UR -82-3275

$$
\operatorname{cong}-83040.5-4
$$

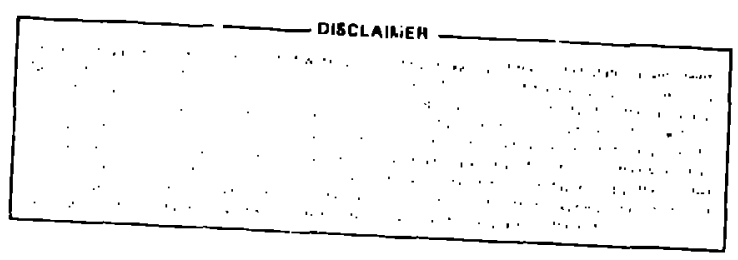

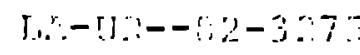

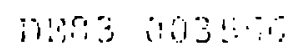

TITLE: DESIGN, CONSTRUCTION, AND INITIAL OPERATION OF THE LOS ALAMOS NATIONAL LABORATORY SALT-GRADIENT SOLAR POND

AUTHOR(S): G. F. Jones, K. A. Meyer, J. C. Her and D. P. Grimmer.

J. S. Dreicer,

SUBmitted to To be presented at the ASME Solar Energy Division Mueting held in Orlando, Florida, on April 19-21, 1983. 
DESIGN, CONSTRUCTICN, AND INITIAL OPERATION

OF THE I OS ALAMOS NATIONAL LABORATORY

SALT-GRADIENT SOLAR PONC

by

G. F. Jones, K. A. Meyer, J. C. Hedstrom,

J. S. Dreicer, and D. P. Grimmer

Los Alamos National Laboratory

Solar Energy Group, MS K571

Los Alamos, NM 87545

To be presented at the ASME Solar Energy Division Meeting held in Orlando, Florida, on Aprii 19-21, 1983. 


\title{
OESIGN, CONSTRUCTION, AND INITIAL OPERATION \\ OF THE LOS ALAMOS NATIONAL LABORATORY \\ SALT-GRADIENT SOLAR POND
}

by

G. F. Jones, K. A. Meyer, J. C. Hedstrom, J. S. Oreicer, and D. P. Grimmer

Los: 4 lamos National Laboratory

Solar Energy Group, MS K571

Los Alamos, NM 87545

\begin{abstract}
A 232. $\mathrm{m}^{2}$ solar pond wis constructed at Los Alamos National Laboratory for the purposc of studying pond hydrodynamics on a large scale and to complemerit the flow visualization and one-dimensional pond simulator experiments that are nngoing at the Laboratory. Design methods and construction techniques, some of which are urique to this pond, are described in detail. The pond was excavated from a scift volcanic rock known as tuff; such rock forms a large fraction of the Los $A$ amos area surfaca geology. Because tuff has a small therm $i l$ conductivity, little insulation was required to reduce perimeter energy losses. In addition, the strength of tuff permitted the pond to be built with verticai side wa' 15 ; this design eliminated local side wall convection in the gradient zone trat is possible with sloping side walls. Instrumentation in the pond consists of traversing and fixed rakes of thermometers and salinity probes, an undirwater pyranometer, and a weather station. The traversing ruke is a wheeler trolley driven vertically on a rectangular rail. Installed on the trulley are coplanar platinum RTOS, a point conductivity probe, and an induction salinometer. The stationary rake supports 2.8 thermocouples and 2.8 sample fluid withdrawal taps located every $10 \mathrm{cIn}$. About $12.7 \mathrm{~T}$ of sodium chloride has been introduced and is nearly dissolved. A 120-cm-thick salinity gradient was establisted and the pond is heating. Preliminary results indicate a lower-convective-zone heating rate of $1.2^{\circ} \mathrm{C} /$ day during the pond's firct month of operation. Recomnendations on pond design, construction, and instrumentation are presented.
\end{abstract}




\section{INTRODUCTION}

This paper discusses the design, construction, and initial operation of the solar pond at Los Alamo; National Laboratory. This $232 \mathrm{~m}^{2}$ pond is the third facet of a threefold approach to the study of hydrodynamic effects in double diffusive systems, such as solar ponds. The first two facets are flow visualization experiments and one-dimensional laboratory tank tests. Data from these experiments in addition to other data from the literature are used to validate the one-dimensional dynamic performance pond model developed by one of the authors (K. A. Meyer ${ }^{1}$ ). Our particular interest is the boundary layer structure at the interfaces between the convecting and nonconvecting zones, interaction between the zones, and surface zone effects including diurnal heating effects and wind-induced turbulence. A large-scale pond, such as the one tilis paper describes, provides possible insight into several pond physical processes that may not occur in smaller scale laboratory experiments or may be impossible to simulate.

The paper addresses each phase of the solar pond project under separate headings: design, construction, and preliminary results. In addition, individual sertions are provided for instrumentation; salt mixing and gradient establishment; and a final section on construction, design, and instrumentation recommendations.

\section{DESIGN CONSIDERATIONS}

The solar pond at Los Alamos National Laboratory is primarily a research facility. It was built to study pond hydrodynamics on a large scile and to complement the flow visualization and tank tests that äre orgoing at the Laboratory. An acceptable design would accormodate our research experiments as well as include representative diminsions and layer thicklless so that performance results could be applied to other ponds. Furthermore, the overa!l nesign was constrained by funding I Imftations. U:ing this approach, we decided on a square ponc, $15.3 \mathrm{~m}$ on a side excavated to a depth of $3.6 \mathrm{~m}$. We considered a $1.2 \%$ m thick lower convective zone (LC7) and a $1.2 \mathrm{~m}$ nonconvecting zone (NC.7) as representative layer thicknesses. A 10-cm-thick upper convect ive cone (UCi.) was included to give an overall pond depth of 2.5 r.. The LC2 was destgned for a salinity of 72 by wright sodfun chloride (NaCli).

The inalerial from which the pond was excavated was not soli or clay as with most other ponds, bul a lightwe lght, frialsle volcanle rock known as tuff: 
such rock forms a major fraction of the Lus Alamos surface geology. It is because of tuff ihat the Los Alamos National Laboratory solar pond is unique among other pona. First, tuff has a relatively small thermal conductivity (about $0.05 \mathrm{~W} / \mathrm{m}^{\circ} \mathrm{C} \mathrm{c}$. twice that of polyurethane foam) which implies that little, if any, insulat: on is required to minimize pond perimeter heat losses. Second, the strength of he tuff is sufficient to permit vertical pond walls. Vertical walls insure that the horizontal isosalinity planes in the NCZ remain horizontal and do not bend downward at the pond edges as would occur in a pond with sloping walls; thus, possible local convection at the walls caused by this phenomenon is eliminated. Because of these factors we expect salt and heat transport processes in the Los Alamos National Lahoratory solar pond to be neariy one-dimensional. The disadvantages of vertical walis are that excavation is more difficult, liner stresses are usually greater, and more shadowing of the pond is possible when compared with a solar pond with sloping walls. The overall relative inerit of vertical walls will be determined as pond operation continues.

The pond was designed with its sides aligned in the north, east, south, and west directions, respectively. The location of the pond facility was determined by a number of factors: close proximity to the existing solar energy laboratory, relatively inexpens ive acces:ibility to electric power and water, and a level area on which the main pond ant evaporation pond could be located. We decided on a wooded area on a rim of a nearby canyon, accessible from the exicting solar energy laboratory by a 1-min car ride: and equipped with water and power supplies within $150 \mathrm{~m}$. However, Lhe area sloped gently toivards the canyon $r i m$ with a vertical drop of $4.3 \mathrm{~m}$ in a $60-\mathrm{m}$ horizontal distance. The? site had to be leveled hefore pond excavation could iegin.

The evaporation pond was designed to be $28-\mathrm{m}$ long by $9.7-\mathrm{m}$ wide and $1.1 \mathrm{~m}$ deep at its shallowest location; the long dinension is in thir easi-west. direction. All the walls are verlical (to conserve yround area) except for the west end, which was sloped at a $16^{\circ}$ angle into the pond. This ramp pro vides access into the pond for sall removel and mainterlance.

During the design phase of the profect, computer simulations wern per formed t.o e.sel linate rates of heat los: from the bottom and side wallis of the

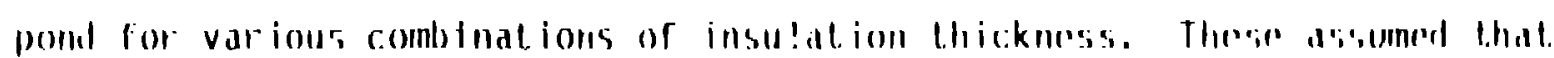

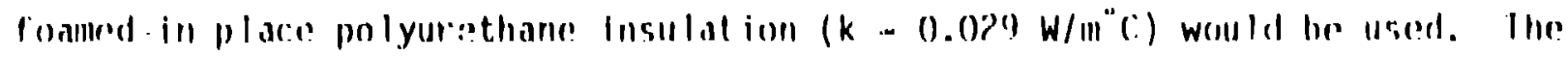

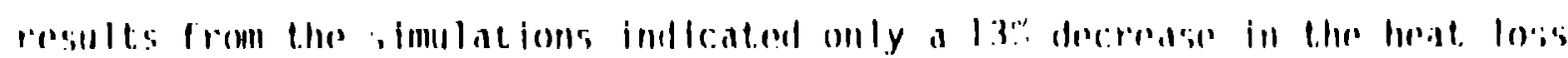


rate wilen proceeding from the case of 'o insulation to the case of a $15.3-\mathrm{cm}-$ thick layer on the side walls and on the fioor for a distance of one meter from the walls. The apparent insensitivity of heat loss to insulation thickness is due to the small thermal conductivity of tuff, which is approximately twice that of the insulation. In comparison, the conductivity of moist, sandy soil can be more than 100 times as large. Thus, insulation to reduce perimeter heat losses was judged to be ineffective here. Nevertheless, to provide a smoth surface on which to install the maill pond's back-up vapor barrier and primary liner we decided to install a 7.6- cm-thick layer of insulation on the pond side walls.

\section{POND CONSTRUCTION}

Construction began in October 1981; first, a bulldozer was used to grade the site, after which a large backhoe excavated the main and evaporation ponds (Fig. 1). The vertical side walls in both ponds were cut by the edge of the backhoe's bucket, for the most part without incident. In two areas, however, fractures in the tuff resulting from tree roots caused some of the tuff to ortak away. The voids caused by these breakouts were eventually tilled with polyurethane insulation blocks held together with foamed-in-place polyurethane. After the ponds were excavated, a $30.5-\mathrm{cm}-$ deep square trench was dug into the tuff around each pond's edge for burying the edges of the liners. The inner edge of each trerch was $107 \mathrm{~cm}$ from the pond rim. Ne.it, concinuous rows of sanubags, each bag weighing $2 ? .6 \mathrm{~kg}$, were laid along the rims of the main pond and the evaporation pond. The bags overhunl the pond rims slightly to provide: smooth, large radii supports on which 1 iner'; would rest. Six holes were then drilled in the main pond for the heat flux meters; one in each of the pond walls and two in the floor. Compressed nitrogen was blown into each holl: as the drilling procecded; this was nec essary to prevent the powdered luff from biading the masonry drili bit in the rock. The heat flux meters were installed after drflling was completed and the therinocouple wires from them were run in tha perimeter trench to a common point close to the future location of the data ac juisition shati.

The insulation work began ill carly June 198\%, after a winter of sollcit.ing and evaluating hids and awardlng the contract. When the tuff breaknut area'; were filled, the contractor applied a 7.6.cem thlck layer of polyurethane 
foam (2.5 $\mathrm{lb} / \mathrm{ft}^{3}$ nominal density) to the pond walls (Fig. 2). The evaporation pond raceived a thin coating of insulation in the region of the sandbags to smooth the rocky edge. The insulation in the main pond was applied from the rock floor up to the sandbags, where the thickness was gradually reduced as it was applied over the bags. This provided a smooth, well-rounded surface on which the main liner would rest.

Next, a 0.5-Im thickness of Hypalon ${ }^{2}$ (a chlorosulfonated polyethylene) was applied with roliers over the entire insulation surface area to serve as a vapor barrier for the walls (Fig. 3). After this was completed, ahout $15 \mathrm{~cm}$ of smooth, rock-free plaster sand was dumped onto the pond floor and spread out evenly. A sheet of 0.5-mm-thick polyvinyl chloride (PVC) was then laid over the sand and run up each wall for a distance of about $30 \mathrm{~cm}$, overlapping the Hypalon coating this distance. Smooth-headed roofing nails were then pressed through the PVC and the Hypalon coating into the insulation to hold the edges of the PVC flush against the Hypalon. After a primer was appiied to the PVC, the Hypalon coating was then extended down over the edyes of the PVC a distance of about $8 \mathrm{~cm}$. In many locations, the primer tended to warp the PVC edges so that they were no longer flush with the Hypalon; these areas were caulked to ensure that the PVC-Hypalon joint was leaktight. The back-up liner was now complete.

Before the ma in liner was installed, a second layer of plaster sand, 6.4-cm thick, was dumped onto the PVC liner and spread evenly. Four leak detectors were inbedded in this layer and their locations from the walls measured and recorded.

The Hypalnn ma in liner of 1.2-mm thickness was shipped to us in three preces; two pieces $6.3 \mathrm{~m}$ by $16.5 \mathrm{~m}$ were to te instalied on the east and west vertical walls, and one piece 27.8 in by $16.3 \mathrm{~m}$ was to be run down the south wall, deross the pond flooi and up the nurth wall. The liner installation went smoothly with the help of only an outside contractor's forcman and six laborers (Fig. 4). The only heavy equipinent required was used to help unfold the largest section of the liner. The liner was installed in about $3 \mathrm{~h}$, with ficld seaming and leak lesting taking another $n \mathrm{~h}$. We delayed burying the maill pond liner until after sime: salt. and water were in the pond to prevent. over-itrairing the vertical sections of the liner. The main yond now neared completion, lacking enly the inst.allation of the dif.user and instrumentation. 
The evaporation pond liner consisting of 0.9-mm-thick CPER (chlorinated polyethylene reinforced with polyester) was installed by the Laboratory's service contractor. It was supplied to us in one piece $30-\mathrm{m}$ long by $15.5-\mathrm{m}$ wide. The floor of the evaporation pond was first swept clean of large rocks that could puncture the liner. A dozen laborers worked iogether for about $1 \mathrm{~h}$ to drag the partially unfolded liner across the pond's width. The corner areas were then folded neatly to provide a good form fit. After ensuring that sufficient slack was provided for in the vertical sections of the liner, the liner edges were turied in tine perimeter trench and the trencin backfilled and compacted.

While pond insulation work was in progress, a passive solar shed was built to house the data acquisition and experiment control systems. The shed is square in plan view, measuring $2 \mathrm{~m}$ on a side; it is loca'ed on an elevated bank of tuff about $8 \mathrm{~m}$ west of the main pond's west bank. In addition to housing the data acquisition system, it also served as an on-site storage room for tools during the construction of the pond and afterward for pond instrumentation and maintenance. The above-water pyranometer was mounted on the shed's near-horizontal roof, this area being the least susceptible to shadowing.

\section{INSTRUMENTATION}

Instrumentation for the solar pond consists of an Eppley Model 8-48 underwater pyranometer ${ }^{3}$, traversing and fixed salinity and temperature measuring rakes, and a weather station. The traversing rake is a 316 stainless iteel wheeled trolley (see Fig. 5) driven vertically at a rate of $0.9 \mathrm{~cm}$ per mill on a 316 stainless steel rail measuring $2.5 \mathrm{~cm}$ by $1.3 \mathrm{~cm}$. Installed on the trolley are two 100 -ohm platinum resistance thermometers (RTD) ${ }^{4}$, a platinum point conductivity probe ${ }^{5}$, and a Beckmán induction salinometer. ${ }^{6}$ All instruments were installed in such a way that measurements were taken in the saine horizontal plane. Typically, one or two traverses per day are rin. Each trave:-se provides salinities and temperatures at vertical increments of $0.9 \mathrm{~cm}$. The fixed rake is constructed from $3.8 \mathrm{~cm}$ by $3.8 \mathrm{~cm}, 316$ stairiess stee 1 angle; it supports 78 copper-constantan thermocouples and 28 sample-fluid withdrawal taps located every $10 \mathrm{~cm}$. This rake povides us with instantaneous temperature profiles; fluid withdrawal provides perlodic in situ recalibration of the point probe and very accurate salinity profiles. Both rakes rest. on 3.2-mm-thick squar: base plates of 316 stainless steel, each having a side dimensior. of $61 \mathrm{~cm}$. A 6.1 - mm-thick layer of neoprene rubber was installed on the bottoms 
and sides of each plate to prevent damage to the main liner; top supports were provided to prevent swaying. The weather station consists of a horizontally mounted Eppley Model 8-48 pyranometer ${ }^{3}$, a MET-ONE wind anemometer and planer wind direction indicator ${ }^{7}$, and a MET-ONE thermally shielded ambient temperature sensor. ${ }^{7}$

Six heat flux meters were installed in the tuff walls of the pond: one in each wall and two in the floor to gauge perimeter heat losses from the pond and to provide us with perimeter temperature distributions in the tuff. Each meter consists of three copper-constantan thermocouples installed equiJistant from each other along a vinyl rod $91.0-\mathrm{cm}$ long. The meters were insialled normal to the perimeter area by drilling into the tuff as described in Sec. 1 II.

Four electric-resistance leak detectors were designed for installation in the sand layer between the primarly and back-up liners: one detector per pond quadrant. Resistances from the detectors are scanned along with the other pond data. Inciependent experiments were performed to determine the resistance of the detectnrs when immersed in fresn water; a leak is indicated if the resistance of any detector falls below this threshold value.

The data acquisition system consists of a Hewlett-Packard Model 87 desk-top computer ${ }^{8}$ and the following Hewlett $P_{i}$ ckard interface equipment: one $3490 \mathrm{~A}$ digital voltmeter, two $3495 \mathrm{~A}$ scanners, two $55303 \mathrm{~A}$ digital-to-analog converte's, one 82901M flexible disc drive, and one $82905 \mathrm{~B}$ line printer. Data from approximately 80 channels is sampled every $50 \mathrm{~s}$ and suitably integrated or averaged before storage on a disc every hour.

Both instrument rakes, the underwate: pyranometer, and the diffuser were designed to be supported from a catwalk which extends about $3.4 \mathrm{~m}$ over the pond from its west bank. The catwalk is $61-\mathrm{cm}$ wide by $4.3-\mathrm{m}$ long with a frame constructed of galvanized structural "H" sections $7.6-\mathrm{cm}$ deep by $3.8-\mathrm{cm}$ wide. The catwalk frame was covered on top by marine-grade plywood 1.9-cm thick with a nonskid surface applied after its top, sides, and hottom were painted. Two 304 stainless steel tubes, 3.5-m long by 8.9-cm nutside diam, rupport the catwalk on the pond floor. The legs are attached to a neoprenerubber-covered haseplate of 304 stainless stee $1,61-\mathrm{cm}$ wide by $.2-\mathrm{m} 10 n_{1}$, at the ir lowcr end and to a mild-steel baseplate, 6l-cm long by $23-c m$ wide, at the ir top. The latter was bolted directly to the catwalk. Two ki...e braces wrie: welded belween the two vertical tubes above the water line to prevent 
catwalk sidesway. The back end of the catwalk is securely anchored to the ground by a poured concrete block; steel handrails and a wooden kickplate complete the safety features.

The instrument rakes were installed about $1.6 \mathrm{~m}$ from the front end of the catwalk with their top sunporting arms bolted directly to it. The underwater pyranometer was suspended from the end of a 3.4-m-long pivoting boom by a 2.4-m-long rod of 316 stainless steel. The boom was mounted at the far end of the cairalk. A marine-type manual winch is used to change the boom's angle which, in turn, alters the elevation of the pyranometer in the pond. Markers were installed on the rod every $\% .6 \mathrm{~cm}$ to gauge the pyranometer's depth.

\section{SALT MIXING AND GRADIENT ESTABLISHMENT}

We took delivery of $127 \mathrm{~T}$ of $98 \%$ pure coarse, granular $\mathrm{NaCl}$ in five truck loads beginning July 8,1982 . An actual salt delivery using a long wooden chute we built is shown in Fig. 6 . After each salt load was delivered, the dissolving process began using water from a local fire hydrant; 6.4-cm-diam fire hose was used to transfer the water from the hydrant to the pond site. During the salt-mixing procedure we found that the combination fog-spray hose nozzle we were using caused too large a flow restriction in the water line. By removing the nozzle and by slightly bending the hose near the water outlet instead, a water jet with a much larger velocity was directed onto the salt pile. We found this mixing technique to be most effective.

After the final salt load was delivered, salt mixing continued by means of two large gasoline-powered centrifugal pumps, each capable of pumping about $400 \mathrm{l} / \mathrm{min}$. They were floa' $d$ on the pond's surface on styrofoam sheets 7.6- $\mathrm{cm}$ thick, 91- $\mathrm{cm}$ wide and 1.9-m long and were designed to take suction from the floor region of the pond and thus improve the salt-mixing rate. When the pumping described above began, there was approximately $1 \mathrm{~m}$ of salt water in the pond. The pumps were run for about $6 \mathrm{~h}$ per day for a 7-day period during mid-July. Simultaneously, the brine was filtered with a Swimquip Model HRP-30 sand filter ${ }^{9}$ charged with $159 \mathrm{~kg}$ of silica sand. The brine was circulated with a Purex Series $A$, Mode 1 AH- 8 bronze centrifugal pump ${ }^{10}$ with a built-in basket strainer. The filter was backwashed with fresh water daily, the backwash effluent being discharged into the evaporation pond.

On July 27 the brine was shocked with algicide as a precutionary measure before the gradient was established. An additional $80 \mathrm{~cm}$ of fresh 
water was added and mixed with the existing salt solution. The following day all salt mixing and filtering was stopped to let the remaining suspended dirt settle to the bottom. The salinity of the brine was then about $18.5 \%$.

The diffuser used to establish the salt gradient was coristructed from two polymethylmethacrylate (PMM) circular disks $6.4-\mathrm{mm}$ thick and about $1 \mathrm{~m}$ in diam. The disks are separated by six evenly spaced radial vanes of $6.4-\mathrm{mm}-$ thick PMM. The vanes maintain a constant gap width between the two disks and add to the structural integrity of the diffuser. Water was suppliad tc the diffuser through a 5.4-cm-diam PVC pipe attached to the upper disk by a PMM flange.

The diffuser was installed on the south side of the catwalk by inserting the water supply pipe into two shimmed ring-type supports; the shims keep the diffiser horizontal. A manual winch, like the one used for the underwater pyranometer, was used to change the elevation of the diffuser in the pond. The completed diffuser is shown in cperation in Fig. 7.

The salt gradient was established beginning August 4 by using a fresh water diffusion method. Starting with $180 \mathrm{~cm}$ of $18.5 \%$ saline water at $25^{\circ} \mathrm{C}$, the following procedure was followed. The diffuser was lowered to a depth of $120 \mathrm{~cm}$ from the pond floor, this depth being the chosen LCZ thickriess. With a flowrate from the diffuser of about $0.17 \mathrm{~m}^{3} / \mathrm{min}$ (this produces an exit velocity of $0.2 \mathrm{~m} / \mathrm{s}$ from the diffuser gap), $5.1 \mathrm{~cm}$ of fresh water were added. Because the fresh water was less dense than the brine into which it was added, only upward mixing occurred. The incoming fresh water temperature, which was lower than the brine temperature, had no adverse effect on the stability of the layer(s) below the diffuser because the small incoming flow of fresh water was rapidly warmed by the large mass of brine. After the first increment of fresh water was added, the diffuser was moved up a distance twice the fill increment $(10.2 \mathrm{~cm})$. Another $5.1-\mathrm{cm}$ layer of fresh water was diffused into the pond at this point and the procedure was repeated a total of 12 times until the pond's depth was about $2.4 \mathrm{~m}$. A $10-\mathrm{cm}$ layer of fresh water added $t$, the surface completed the gradient establishment.

We encountered, during this procedure, the problem of entrained air bubbles in the fresh water supply and associated problems that could occur from disturbances that probagated downward as the bubbles left the diffuser outlet. The problem was not with air in the water supply sy'stem, as we had originally thought, but with air in the diffuser itself. The hose connection 
to the diffuser supply pipe included a series of fittings that were located $1.8 \mathrm{~m}$ above the catwalk surface; thus, the water supply hose ran from the ground, a minimum of $1 \mathrm{~m}$ ahove the pond's surface, to the $1.8 \mathrm{~m}$ height. At the low rate of flow, the diffuser pressure drop was insufficient to prevent siphoning between the pond surface level and the supply hose on the ground. Because of this, a negative gauge pressure existed at the upper part of the water supply system. The fittings installed in this part of our system were permitting air to enter the diffuser. The protlem was corrected by adding a stainless steel ball valve in the diffuser supply pipe and adjusting it so that siphoning was suppressed. No air entrainment occurred after this corrective procedure was performed.

\section{PRELIMINARY RESULTS}

The pond began warming from a temperature of $25^{\circ} \mathrm{C}$ and a saiinity of about 18.5\% when gradient establishment began on August 4 . At that time, although most of the salt had dissolved, a thin layer remained visible on some sections of the pond floor. However, dirt that settled on top of the bottom salt layer darkened the floor consider bly. As Figs. 8 and 9 show, on September 3 the LCZ salinity and temperature were $21 \%$ and $50^{\circ} \mathrm{C}$, respectively. Inspection of the LCZ temperature profile in Fig. 9 shows the existence of a second gradient zone extending from the pond floor to about $20 \mathrm{~cm}$ above it. This gradient was caused by ihe presence of undissoived salt and was eliminated by using the diffuser and pumping salt water from the floor region to a region just beiow the LCZ interface at a low velocity. Because convective motion in the LCZ was not sufficient to suppress the regrowth of the secondary gradient under the then existing pond conditions, periodic pumping was necessary. The last temperature point plotted in Fig. 9 is that measured by a thermocouple exposed to air above the pond.

The rates of increase in the LCZ temperature and salinity are shown in Figs. 10 and 11 , respectively, for the period of August 8 through 0rtober 17 . Figure 10 indicates a large rate of LCZ heating in the beginning of the pericd of about $1.2^{\circ} \mathrm{C} /$ day. At the end of the period, the increased rate of losses through interface and pond perimeter decreased this value to about $0.25^{\circ} \mathrm{C} /$ day. Figure 11 shows a larye rate of increase in the LCZ salinity until Julian day 243, after which a smaller rate of increase occuried. Jefore day 243, pumping 
was performed to eliminate the secondary gradient and the resulting mechanical agitation caused the rapid rate of dissolution during this period.

\section{RECOMMENDATIONS}

From our experience to date, we make the following recommendations on solar pond design, construction, and instrumentation:

1. If a pond with vertical or near vertical walls is considered, it is necessary to takn precautions to minimize liner tensile stress. We recommend the placement of sandbags or a similar material around the bottom perimeter of the pond before liner installation to increase the bending radius of the liner at this location. This is especially important if field or factory seams are located at this point and if a soft sand or soil base is used under the liner. Shifting of the sand or base away from the wall or vertical settling may place large strains on the lire. In addition, the pond may be filled to its operating level before burying or securing the liner in the pond banks. This permits both adequate settling of the base without straining the liner and the release of air tranped between the liner and the pond walls.

2. A method for detecting the iccation of leaks in the pond liner, in addition to overall leak detection, should be corsidered during the design phase of the pond. An inexpensive method would involve partial burial of a length of perforated tule (rubber or plastic hose would be ideal) in a serpentine alrangement in the layer underneath the liner. The tube is plugged at the buried end and run above ground at the other end. Upon suspecting a leak (because of a drop in leak-detector resistance or a falling of the pond water level over time as indicated by piotting isosalinity lines), compressed air or nitrogen is carefully introduced into the lub: with sufficient pressure to equal the hydrostatic presiure at the bottom of the pond. The leak locaticns are then found by lucating gas bubble streams fom the liner. Small hole' made in the liner at several places above the water line will permit. the gas to escape and can be easily patched later. 
3. A stationary rake of thermometers spaced incrementally in the vertical direction should be considered as a fundamental component of pond instrumen:ation. Data from such rakes provide instantaneous temperature distributions from which problems such as local convection in the gradient zone (fossibly caused by improper gradient maintenance) and other pond phenomena may be detected.

4. Severe problems continue to exist with electric conductivity point probes (see Ref. 5). These center on two aspects of the method as follows:

(a) the sensitivity of the measured specific conductivity to the easily-perturbed electrical condition of the platinized point probe tip requiring continual probe recalibration; and

(b) the saturation effect of the specific conductivity as a function of salinity at large $(\$ 20 \%)$ values of salinity for all temperatures. Constant probe recalibration and the probes' inaccuracy in large salinity environments dictate that other methods of measuring salinity be pursued. Further work is required on inexpensive, simple instruments to accurately measure in situ point density wit' in a contained electro'yte solution

\section{ACKNOWLEDGMENTS}

ihe authors would like lo acknowledge the following people who have made significant contributions to the Los Alamos National Laboraiory Solar Pond: L. Brewer, M. Burkett, L. Dalton, J. Haucer, B. Ketchim, and J. Tafoya. 


\section{REFERENCES}

1. K. A. Meyer, "A One-Dimensional Model of the Dynamic Layer Behavior in a Salt Gradient Solar Pond," AS/ISES, Proc. of the Annual Meeting, Solar Energy Society Meeting, Philadeiphia, PennsyTvaria, May 26-30, 1981 (American Section of the International Solar Energy Society, Newark, Delaware, 1981), pp. 763-76\%.

2. Information on Hypalon is available from Steveris Elastomeric and Plastic Products, Inc., subsidiary of J. P. Stevens and Company, Eas thampton, MA 01027. Fabrication of our liner was by Watersaver Company, Inc., Denver, CO $8021 \bar{\sigma}^{\circ}$.

3. Intormation on pyranometers is available from the Eppley Laboi atory, Inc., 12 Sheffield Avenue, Newport, Rhode RI 02840

4. Resistance thermometer and other temperature measuring instrumentation information is available from Omega Engineering, Inc., l Oinega Drive, Stanford, C.T 26907.

5. D. P. Grimmer, G. F. Jones, J. Tafoya, K. A. Meyer, and T. J. Fitzyerald, "Developinent of a Point-E lectrode Conductivity Salinometer with High Spatial Resolution for Use in Very Saline Sclutions," in preparation.

6. Information on the induction salirometer is availalsle from Beckman Instruments, Inc., 89 Commerce Rodd, Cedar Erove, N. 07009.

7. information on weather station instrumentation is available fron MCI ONF, 154 San Lazaro, Sunnyvale, CA 94086.

8. Data acquisition system information is available firom Hewlett-Packard Company, 1101 Embarcadero Road, Palo Alto, CA 94.303.

9. Information on the HRP-30 sand filter is available from Swinguip company, 3301 Gilman Road, F.1 Monte, CA 9173?.

10. Information on the Series A Model AH.83 p!mp is available Prom Purex Poul Produrts, 18400 E. Mohr Avenue, City of Industry, CA 91/49. 


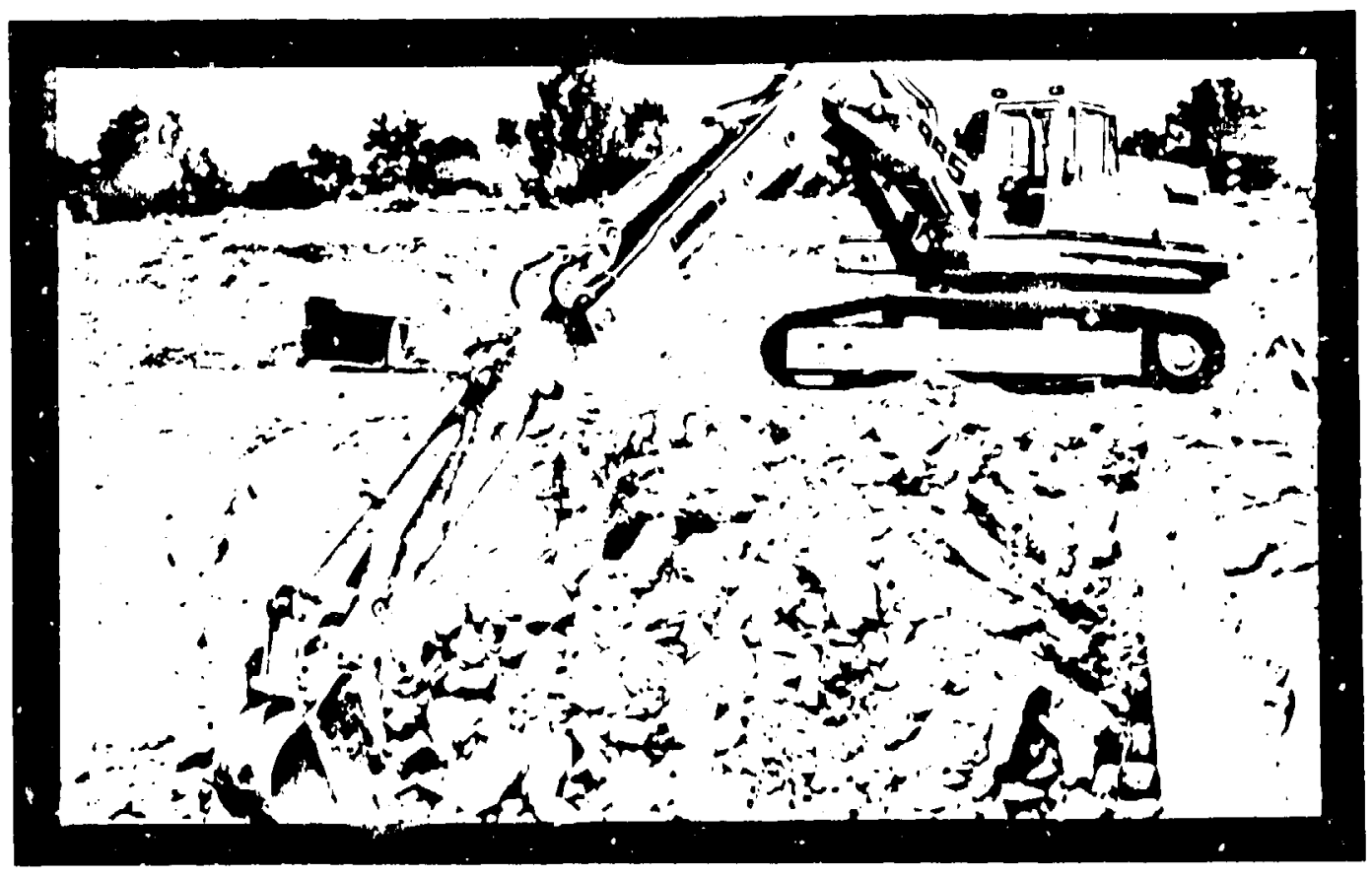

Fig. 1. Backhoe excavation of the ma in pond showing the vertical rock ("tuff") walls and broken rock on the pond floor. View is look ing towards south.

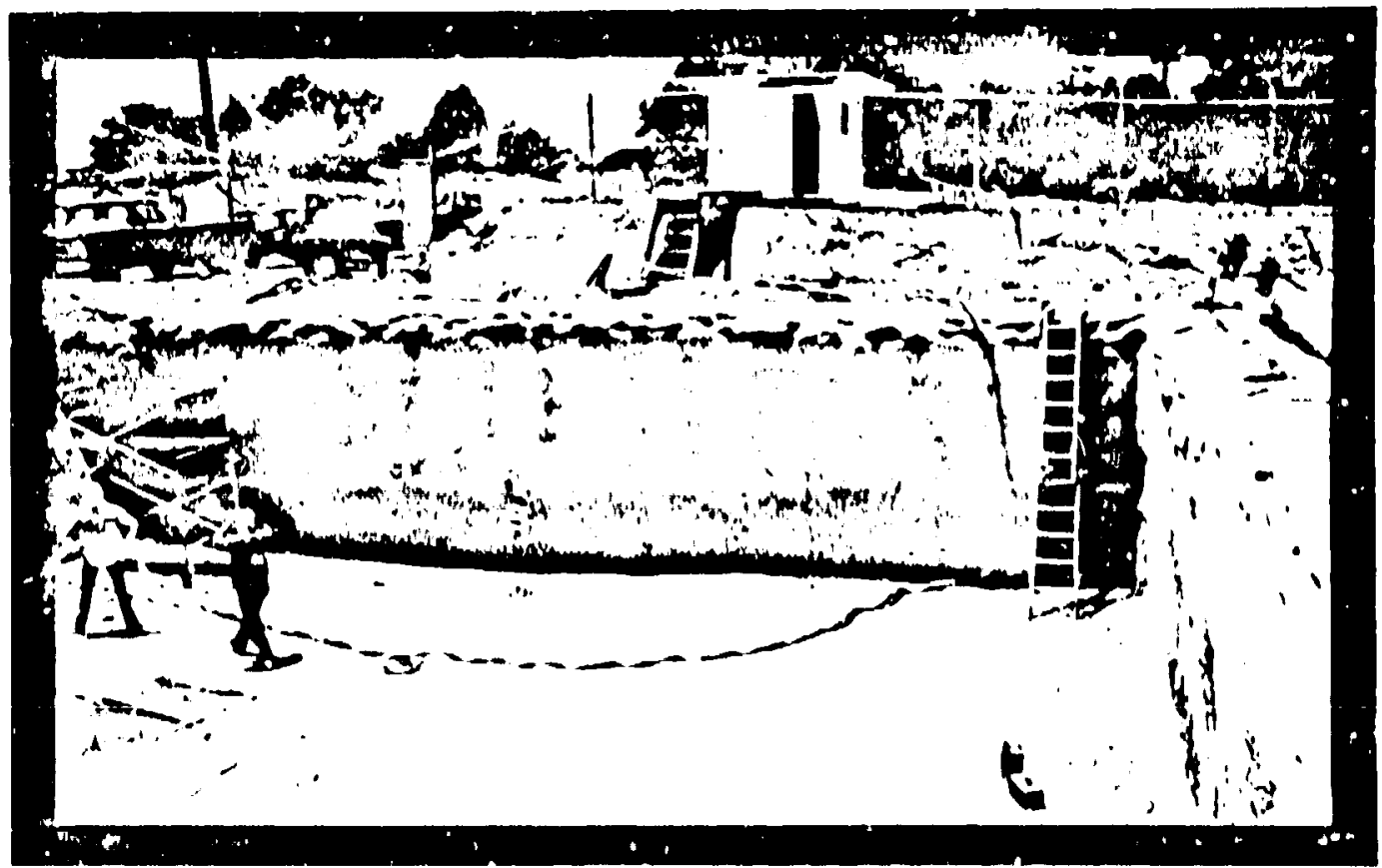

Fig. ?. Insulation of the main pond vertical sidewalls with $7.6 \mathrm{con}$ of polyurethane foam. Sandhage line the pond rim. The trench into which the liner eleges are to be burfed is vlsikle on the rar right. The data ac gufsitfen shed is in the backyround. Vlew i looklng towards WSW. 


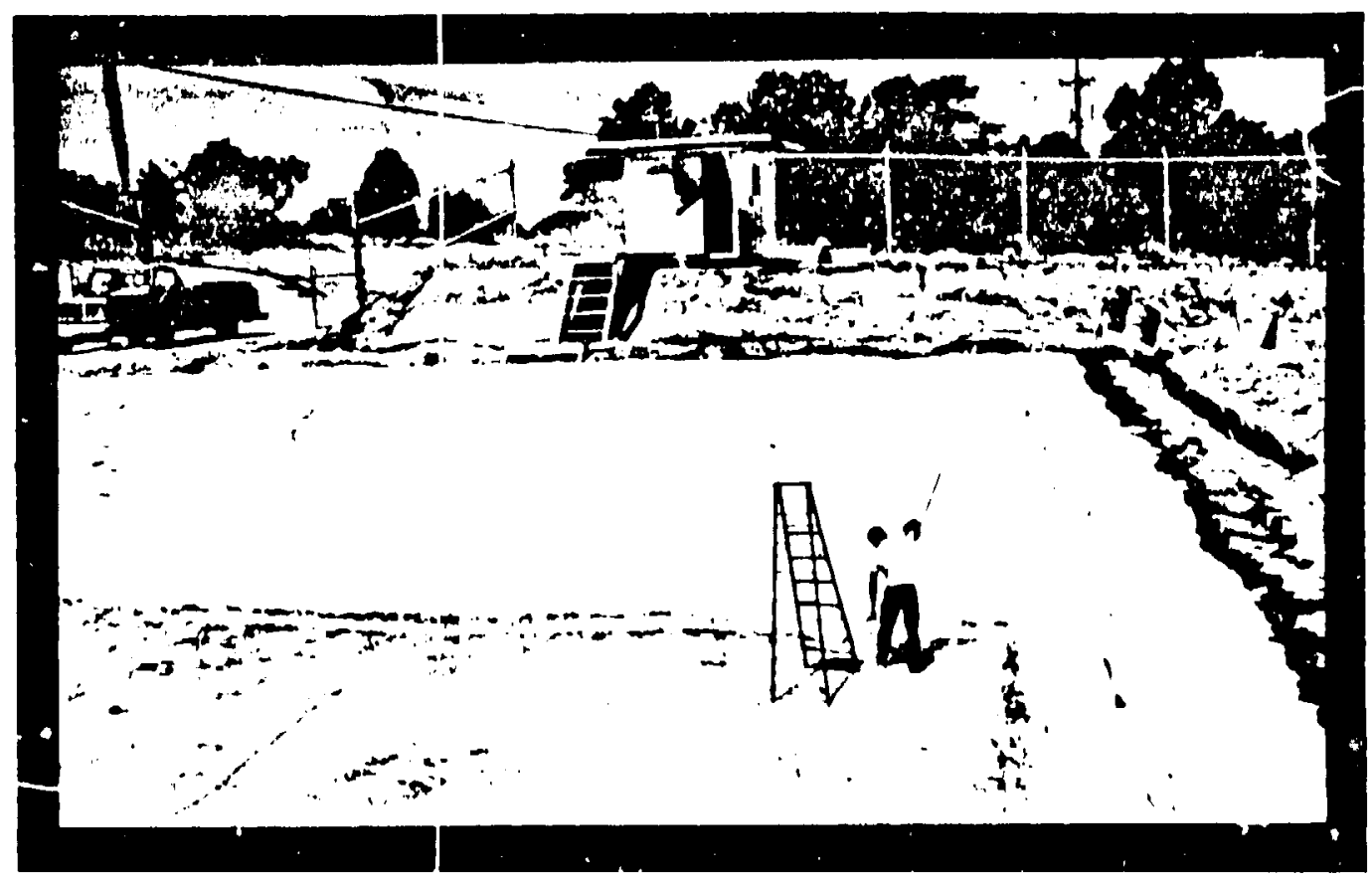

Fig. 3. Hypalon vilpor barrier coating being applied to polyurethane insulation.

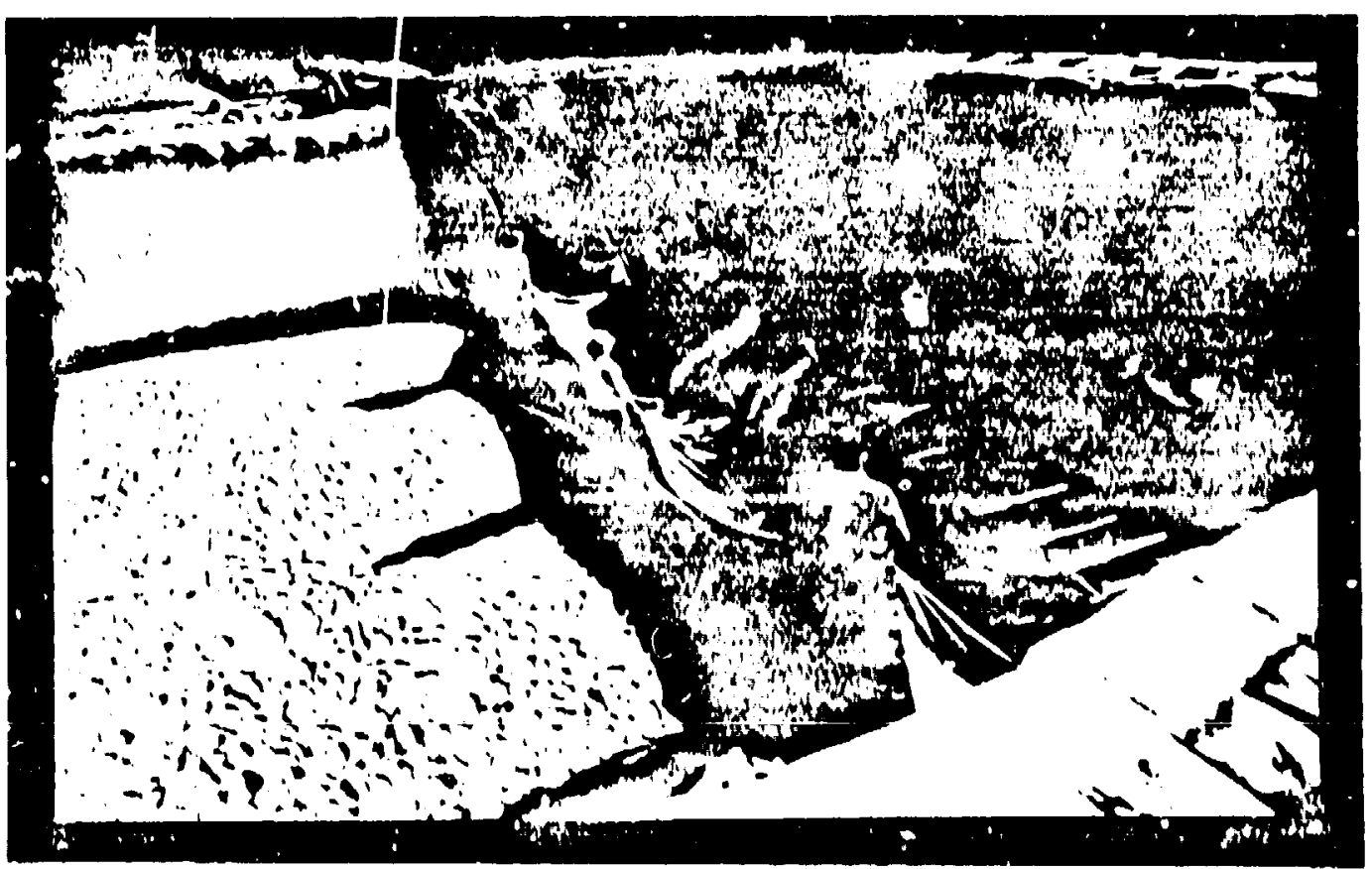

Fly. 4. Hypalon main liner inctallation. Workers mull un folded liner from east to werit sides of pond. The. $6.1 \mathrm{~cm}$ "hick layer of plactor sand they w.llk on anv eres the PVC backup limer. The far edege at this liner is visible as it protruder from the sand at the floor's horth end wheres it lis bonderd to lhe llypalon vapor harrier. Vapor barrerer and insulde ion: coverend

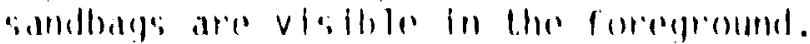




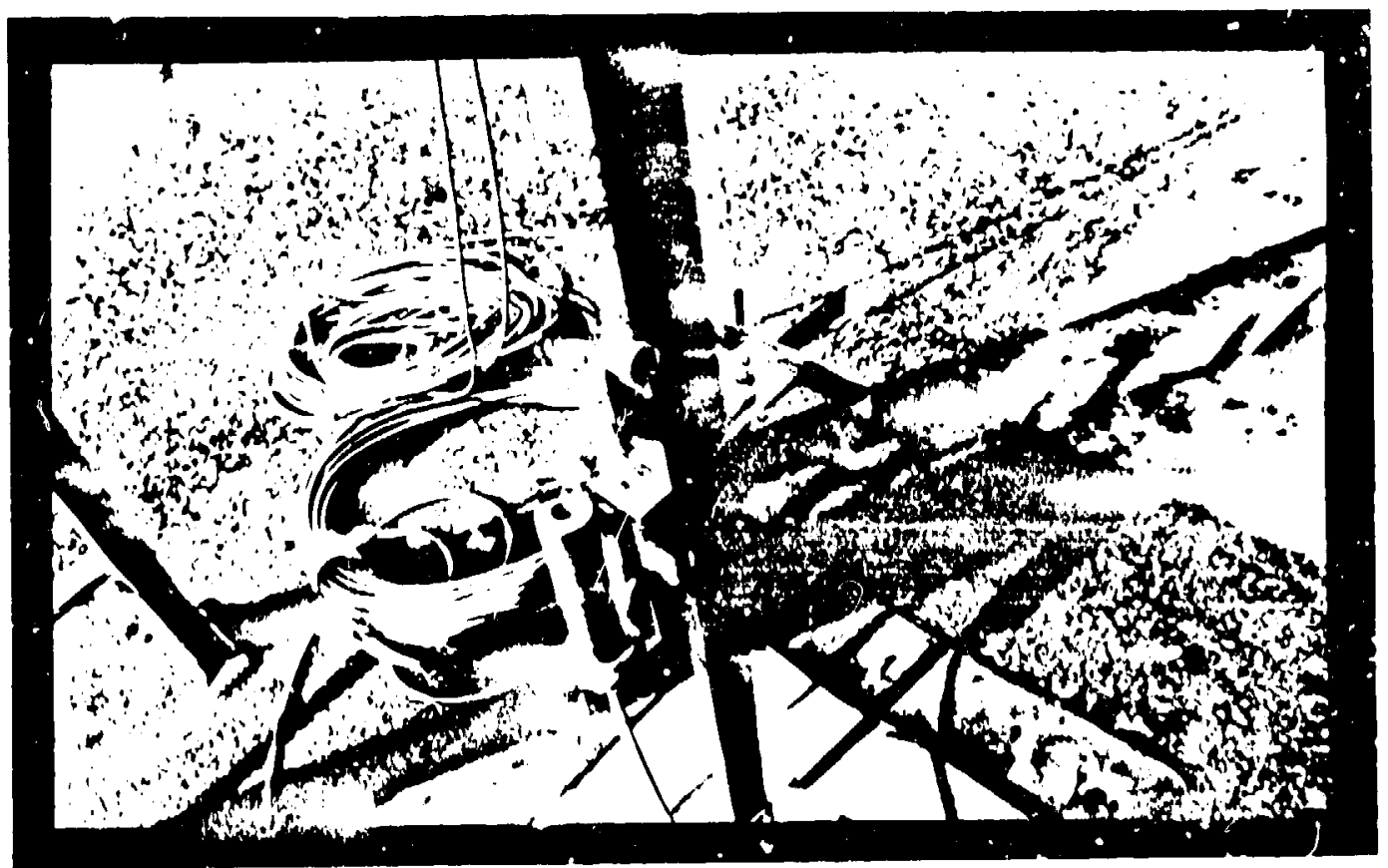

Fig. 5. Traversing rake trolley, rail, and part-view of rubber-covered basepiate before installalion in the pond. The induction salillity probe is mounted on the trolley's front while brackets for two resistance temperature detectors and a platinum point probe are in the back. The trolley wheels are white teflon and all else is 316 stailless steel.

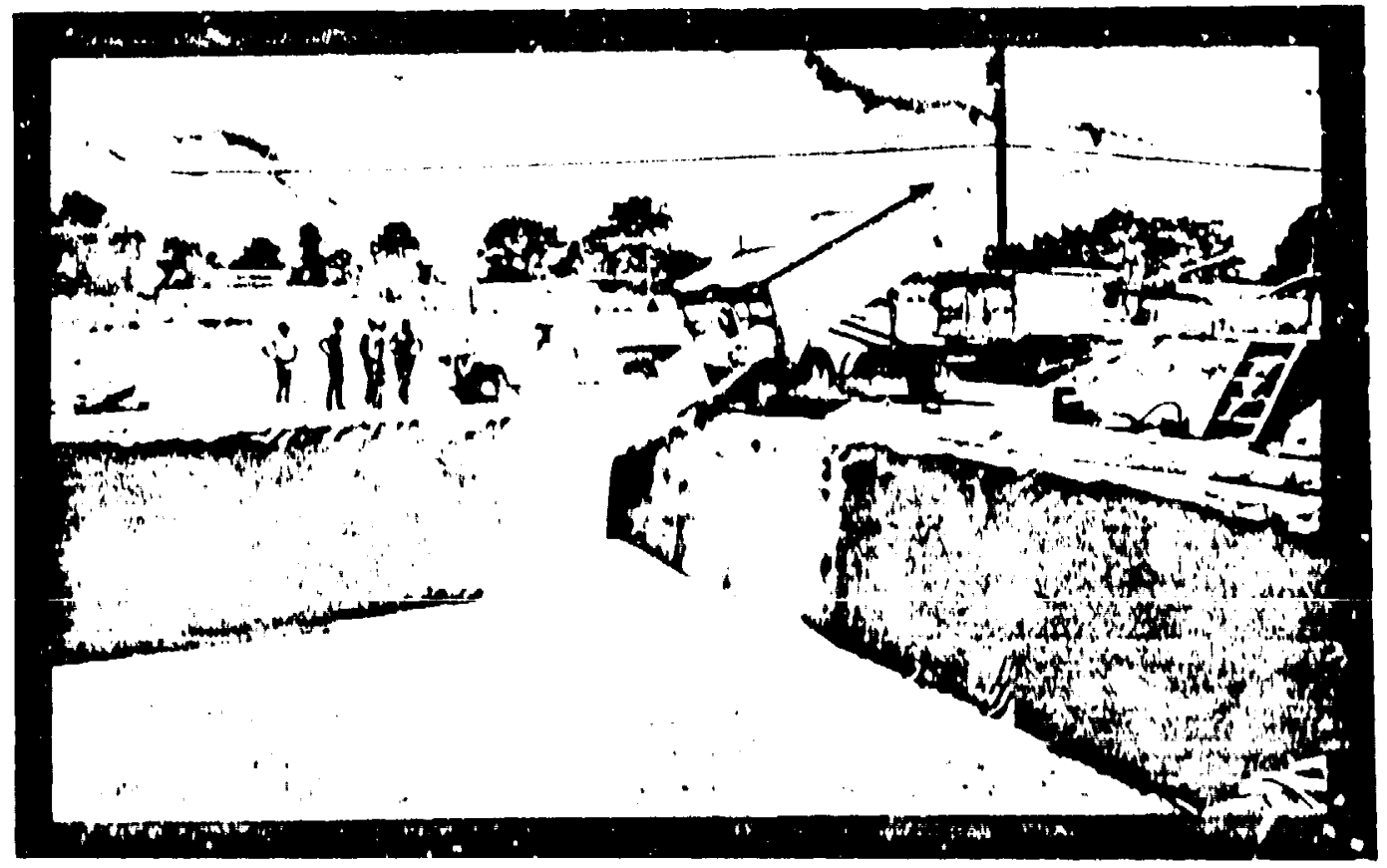

1:ig. 6. Salt dumping operation showing the woolen chute that was made to chanmel the salt to the pond's floor. The finished maln liner is also shown here. View is look ine toward the SW. 


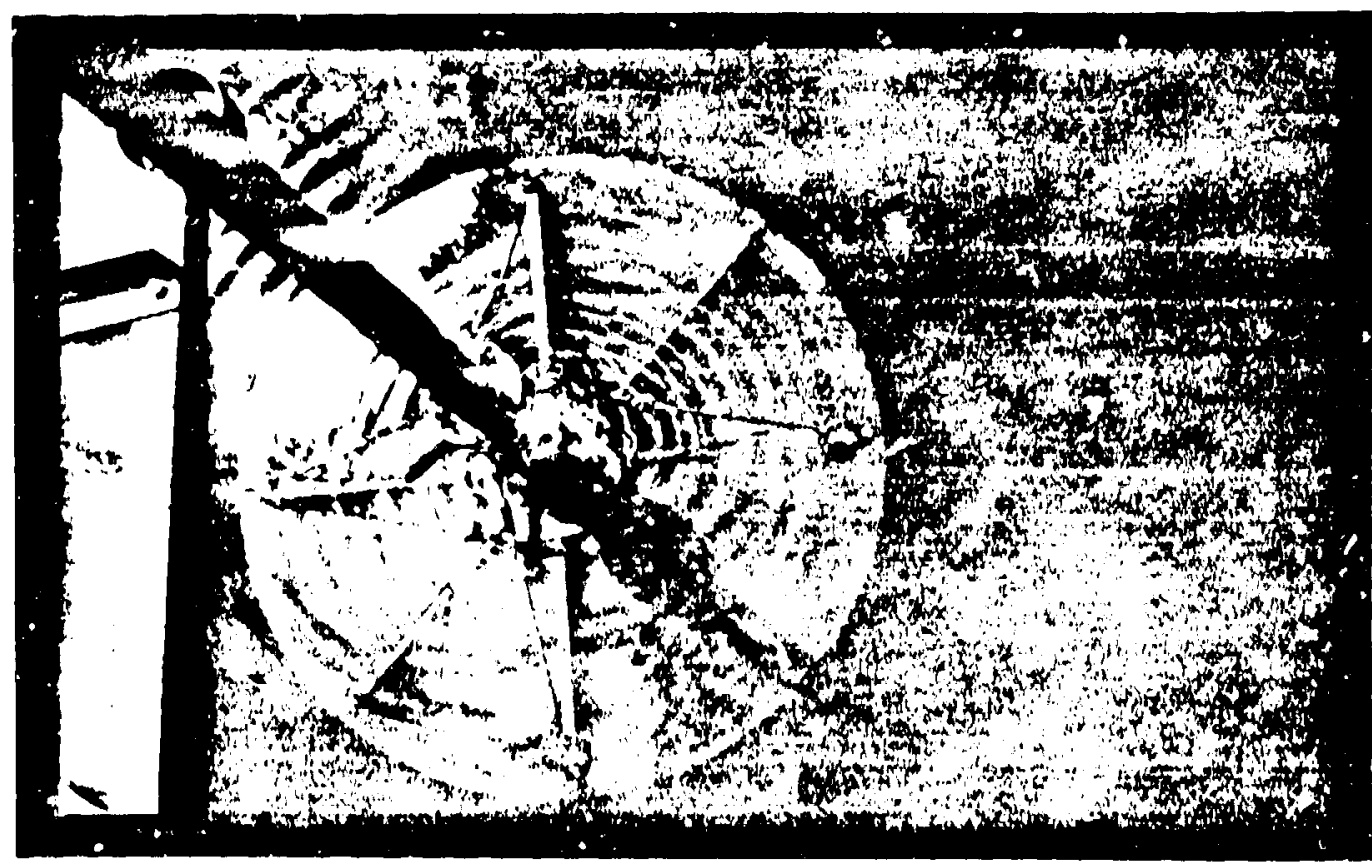

Fig. 7. Overhead view of diffuser from the catwalk while the final fresh water increment was being added. Water supply pipe extends vertically through its lower support. The pressure reducing valve is visible just above the diffuser plates. 


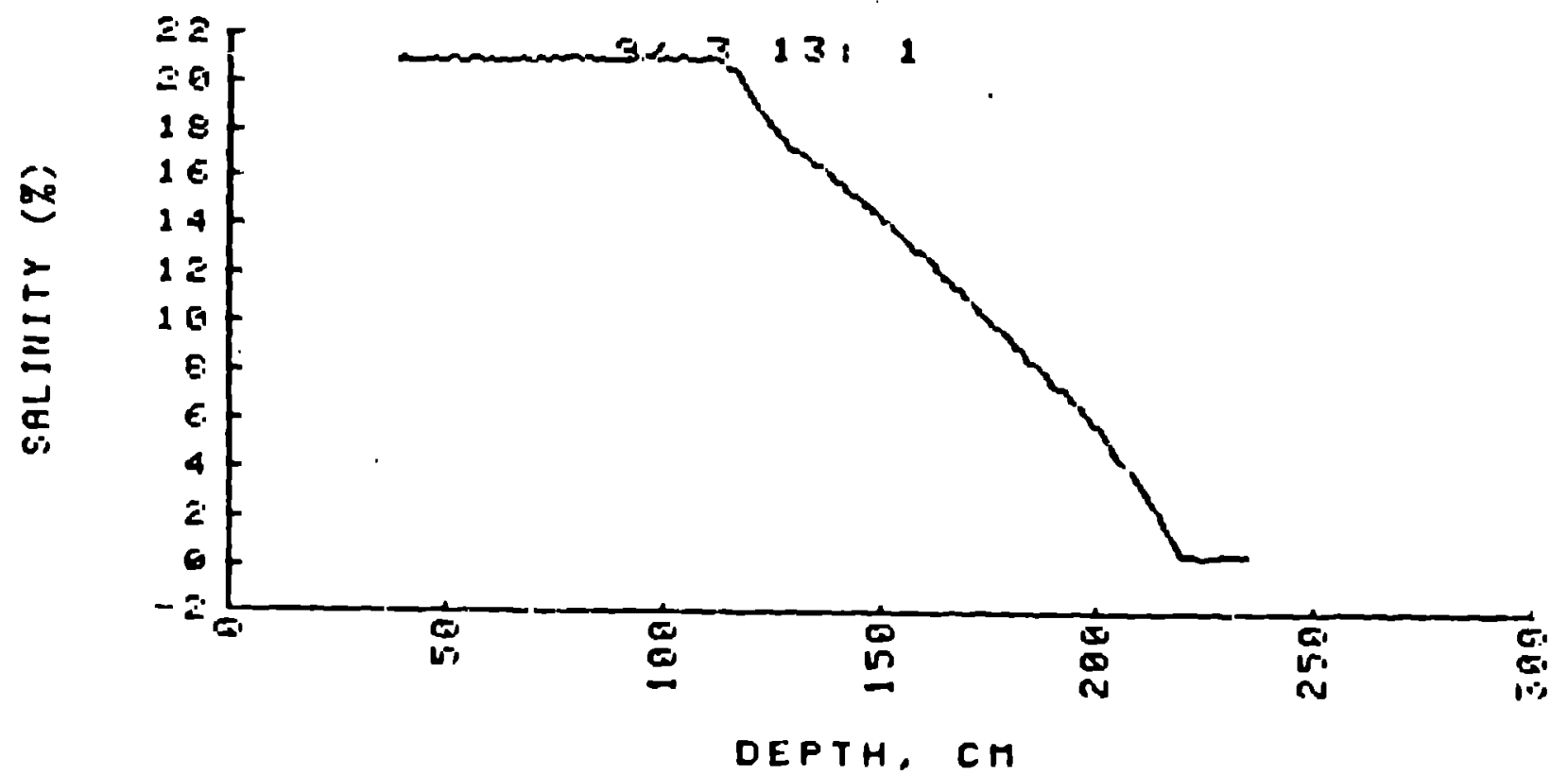

rig. 8. Salinity profile for Septenber 3, 1982. Denth is measured from the pond's bottom.

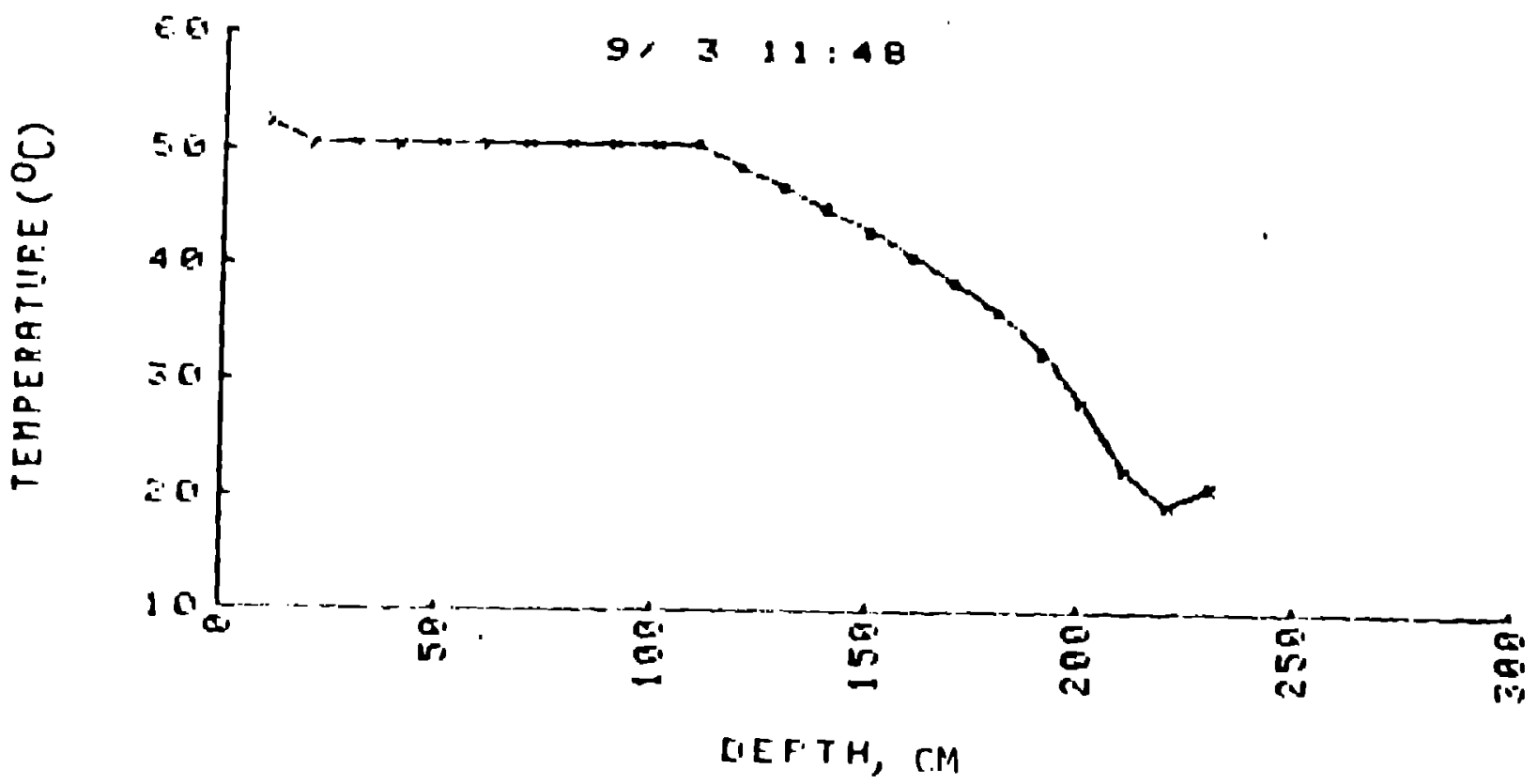

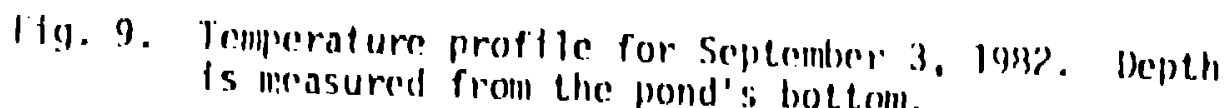




$$
E
$$




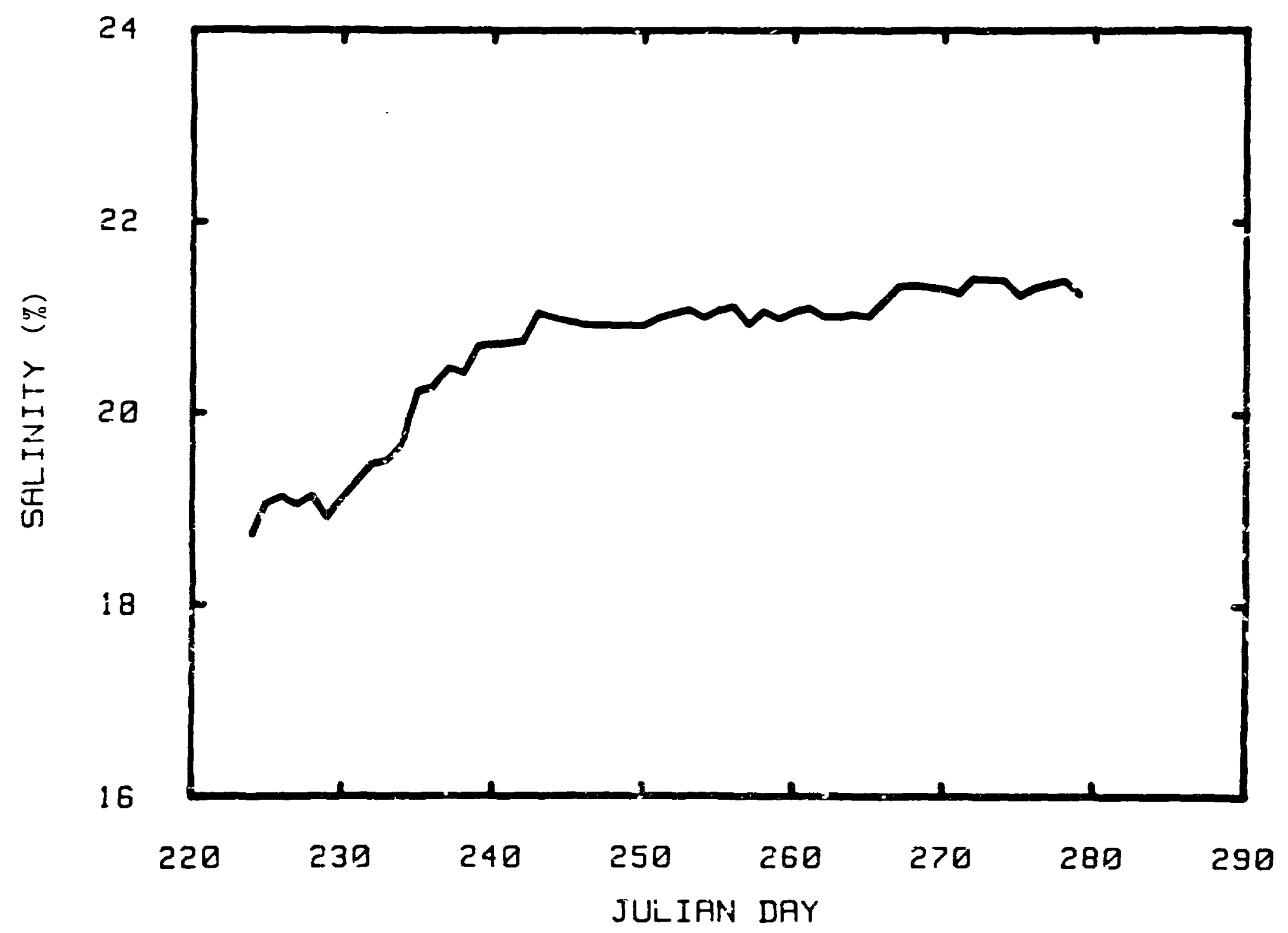

Fig. 11. Salinity of lower convective zorie for August 8 through October 17, 1982. 